\title{
Mutation at position -132 in the islet amyloid polypeptide (IAPP) gene promoter enhances basal transcriptional activity through a new CRE-like binding site
}

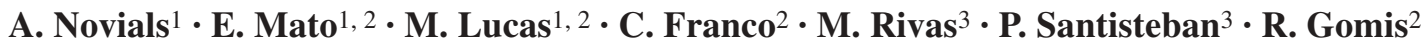 \\ ${ }^{1}$ Diabetes Institute Sarda Farriol Foundation, Barcelona, Spain \\ ${ }^{2}$ Endocrinology and Diabetes Unit, Department of Medicine, Hospital Clinic, Biomedical Research Institute August Pi Sunyer \\ (IDIBAPS), University of Barcelona, Barcelona, Spain \\ ${ }^{3}$ Biomedical Research Institute Alberto Sols (CSIC), Autonomous University of Madrid, Madrid, Spain
}

\section{Abstract}

Aims/hypothesis. Mutations in the islet amyloid polypeptide $(I A P P)$ gene may play a potential role in the abnormal regulation or expression of the peptide. The aim of this study was to determine the functional role of the $-132 G / A$ mutation reported in the promoter region of the IAPP gene in a population of Spanish Type 2 diabetic patients.

Methods. We investigated the transcriptional activity using MIN6 cells and luciferase reporter plasmids in several culture conditions. Key regulatory elements of the IAPP promoter region were also analysed by electrophoretic mobility shift assays (EMSA).

Results. The mutant construct doubled IAPP transcriptional activity $(p<0.001)$. Both constructs showed severely reduced promoter activity (four-fold decrease) in the presence of verapamil and diazoxide. In contrast, IAPP promoter activity was doubled after in- cubation with forskolin or dexamethasone, regardless of the glucose concentrations in the culture media. EMSA revealed that the -132 G/A mutation increased the binding affinity through two DNA-protein complexes. In addition, a cAMP-responsive element binding protein (CREB) was identified by super-shift EMSA.

Conclusions/interpretation. Our studies show that the wild-type and the mutant constructs are regulated in a similar pattern under all conditions, strongly indicating that the $-132 \mathrm{G} / \mathrm{A}$ mutation increases basal but not inducible transcription. These results may be explained by new binding to the mutant region through CREB and other transcription factors not yet identified.

Keywords Diabetes candidate gene - Gene promoter mutation - Gene transcription - Islet amyloid polypeptide $\cdot$ Type 2 diabetes

\section{Introduction}

Islet amyloid polypeptide (IAPP), also known as amylin, is the primary constituent of amyloid deposits, which are found in pancreatic islets of patients with

Received: 1 December 2003 / Accepted: 17 April 2004

Published online: 9 July 2004

C Springer-Verlag 2004

R. Gomis (匹)

Endocrinology and Diabetes Unit,

Department of Medicine, Hospital Clinic,

Biomedical Research Institute August Pi Sunyer (IDIBAPS),

University of Barcelona, Villarroel 170, 08036 Barcelona, Spain

E-mail: rgomis@ @linic.ub.es

Tel.: +34-93-2279846, Fax: +34-93-4516638
Type 2 diabetes [1, 2, 3]. Islet deposits may play a key role in beta cell dysfunction and beta cell loss in Type 2 diabetes and are characteristic of the disease $[4,5$, 6]. The mechanisms responsible for the conversion of IAPP to insoluble fibrils [7, 8], a biochemical feature of amyloidogenesis, are unknown. Overexpression of the peptide has been implicated in islet amyloidogene-

\footnotetext{
Abbreviations: AP-1, nuclear factors activation protein-1 . cAMP, cyclic AMP - CBP, cAMP-binding protein . CRE, cAMP-response element · CREB, cAMP-response element binding protein - CREM, cAMP-response element modulator - EMSA, electrophoretic mobility shift assay · GRE, glucocorticoid response element $\cdot$ HNF3, hepatocyte nuclear factor - IAPP, islet amyloid polypeptide - TTF-2, thyroid transcription factor
} 
sis and Type 2 diabetes. Some models of transgenic mice overexpressing the human IAPP gene form intracellular IAPP fibrils with the subsequent development of hyperglycaemia $[9,10,11]$. The cis-acting elements of the IAPP gene that are required for islet beta cell expression have been identified elsewhere and elicit similar sequences to the promoter region of the insulin gene [12]. These findings demonstrate that insulin and IAPP genes contain similar cell-specific promoter elements that bind identical beta cell nuclear complexes and suggest that they share at least some transcriptional regulatory mechanisms.

A -132 bp $G / A$ mutation in the promoter region of the IAPP gene shows variable frequencies attributed to ethnic differences $[13,14,15,16]$. The frequency of this mutation in our Spanish population was higher in Type 2 diabetic patients than in non-diabetic subjects $(9.7 \%$ vs $1.5 \%, p<0.005)$, which suggests that this mutation plays a role in Type 2 diabetes. The region -138 to -112 of the IAPP promoter, where the mutation is located, has been described as a positive regulatory element of transcriptional activity. However, the transcriptional factors in this region that are involved in the activity of the IAPP gene are unknown.

Here we investigated the functional properties of the $G / A$ mutation, and analysed the effects of glucose metabolism, calcium, cyclic AMP (cAMP) and dexamethasone on the activity of the wild-type and the mutant promoter. We also explored the interaction between the nuclear proteins and this mutant sequence motif to identify some of the transcriptional factors involved in regulation of the IAPP gene.

\section{Subjects, materials and methods}

Cell cultures and treatments. MIN6 cells, derived from transgenic mice expressing the SV40 large antigen under the control of the rat insulin gene promoter [17], were grown in DMEM (Gibco-BRL, Gaithersburg, Md., USA) supplemented with $15 \% \mathrm{FCS}, 100 \mathrm{U} / \mathrm{ml}$ of penicillin, $100 \mu \mathrm{g} / \mathrm{ml}$ streptomycin and $5 \mu \mathrm{mol} / \mathrm{l}$ beta-mercaptoethanol. They were maintained at $37{ }^{\circ} \mathrm{C}$ in a humidified atmosphere containing $5 \% \mathrm{CO}_{2}$ and passaged weekly by trypsinisation with TRIS-EDTA $(0.2-$ $0.5 \mathrm{~mol} / \mathrm{l})$.

The activity of the IAPP promoter was measured and the electrophoretic mobility shift assay (EMSA) conducted (method, see below) after 20 to $24 \mathrm{~h}$ of culture in the presence of 5.5 or $22.7 \mathrm{mmol} / 1$ glucose, or after the following treatments: $11.2 \mathrm{mmol} / \mathrm{l}$ mannoheptulose plus $22.7 \mathrm{mmol} / \mathrm{l}$ glucose, $11.2 \mathrm{mmol} / \mathrm{l}$ 6-deoxy-D-glucose plus $11.2 \mathrm{mmol} / 1$ glucose, $0.6 \mathrm{mmol} / \mathrm{l}$ diazoxide, $100 \mu \mathrm{mol} / \mathrm{l}$ verapamil, $10 \mu \mathrm{mol} / \mathrm{l}$ forskolin and $10 \mu \mathrm{mol} / \mathrm{l}$ dexamethasone.

Oligonucleotides and plasmid constructions. Four plasmid constructs were prepared from human genomic DNA samples obtained from a subject with the $A A$ genotype and a subject with the $G G$ genotype [13] after informed consent and approval by the Hospital Ethics Committee had been obtained.
The amplified regions were cloned into the pGL3-basic plasmid, containing the firefly luciferase reporter gene (Dual-Luciferase Reporter Assay System, Promega, Madison Wis., USA). The oligonucleotides spanned DNA sequences from: (i) -229 to $+38 \mathrm{bp}$, including the IAPP promoter and the exon 1 region (intronless) (forward primer $5^{\prime}$-ACTTCTGCTGTGTATGACACACCA-3', reverse primer 5'-GAGTCCAAGCTTGTATCCACTGGA-3'); and (ii) -229 to +458 bp (including intron 1) (same forward primer, reverse primer 5'-GGATGCCCATGGCTTCTCAAATTTTCTGCAAA-3'). Each clone was verified by DNA sequencing with an ABI 377 DNA sequencer (PerkinElmer, Applied Biosystems, Foster City, Calif., USA).

Transfections and luciferase assays. The plasmid constructs were transfected into MIN6 cells using lipofectamine (GibcoBRL Life Technologies, Paisley, UK) following the manufacturer's instructions. The pRL-CMV plasmid carrying the renilla luciferase gene was used to control the efficiency of transfection. We routinely transfected $1 \mu \mathrm{g}$ of wild-type pGL3 or mutant pGL3, along with $20 \mathrm{ng}$ of renilla-pRL-CMV expression plasmid. The protein concentration of the crude lysate was determined by the Bradford method (Bio-Rad, Richmond, Calif., USA). Firefly and renilla luciferase activities were measured from $6 \mu \mathrm{g}$ of crude cell extract 35 to $40 \mathrm{~h}$ after transfection. The luminescent signals generated by cell extracts after consecutive addition of the two substrates that catalyse firefly and renilla luminescent reactions were measured in a Lumat LB 9507 luminometer (Berthold, Bad Wildbad, Germany). Firefly luciferase activity values were normalised to those of renilla luciferase activity, as a percentage above basal levels of starved cells, and data given are the mean \pm SE of at least three independent experiments. The IAPP promoter activity of transfected cells was examined at low or high glucose, in the absence of any treatment, or after the addition of several agents known to modify beta cell function (see above). All activities were expressed as a percentage of the relative data obtained at low glucose and at high glucose (see corresponding figures).

Electrophoretic mobility shift assays. Nuclear extracts from MIN6 cells cultured in various conditions as described above were prepared, as described by Andrews et al. [18]. Protein concentrations were determined by the Bradford method. Gel shift assays were performed with the mutant and wild-type oligonucleotides derived from positions -138 to -122 of the human IAPP promoter. They were labelled with $\mathrm{T}_{4}$ polynucleotide kinase and $\left(\gamma^{32} \mathrm{P}\right)$ ATP (ICN, Irvine, Calif., USA) and annealed as described elsewhere [19]. For binding reactions, $10 \mu \mathrm{g}$ of nuclear proteins were incubated on ice for $15 \mathrm{~min}$ in a binding reaction mixture containing $40 \mathrm{mmol} / \mathrm{l}$ HEPES (pH=7.9), $200 \mathrm{mmol} / \mathrm{l} \mathrm{KCl}, 0.5 \mathrm{mmol} / \mathrm{l}$ dithiothreitol, $0.2 \mathrm{mmol} / \mathrm{l}$ EDTA, 5\% Ficoll and $3 \mu \mathrm{g}$ of poly(dI-dC). In competition experiments, the unlabelled oligonucleotide was added in excess $(100 \times)$. Labelled oligonucleotide was added to the mixture and incubated for $30 \mathrm{~min}$ at room temperature. For the supershift assay, $1 \mu \mathrm{l}$ of each of anti-cAMP-response element binding protein (CREB) (sc-186x), anti-cAMP-response element modulator (CREM) (sc-440x) and anti-cAMP-binding protein (CBP) (sc-7300x) (Santa Cruz Biotechnology, Santa Cruz, Calif., USA) were added before addition of the probe and incubated for $2 \mathrm{~h}$. As a control, a specific CREB peptide (sc-186p) (Santa Cruz Biotechnology) was used and incubated in the same conditions. The resulting DNA-protein complexes were separated from free DNA on a $5 \%$ polyacrylamide gel (29:1, acrylamide-bisacrylamide). Gels were run at $20 \mathrm{~mA}$ in $0.5 \times$ TBE $(90 \mathrm{mmol} / 1$ TRIS, $90 \mathrm{mmol} / \mathrm{l}$ boric acid, $1 \mathrm{mmol} / \mathrm{l}$ EDTA, $\mathrm{pH}=8$ ), vacuum-dried and exposed to X-ray film at $-70{ }^{\circ} \mathrm{C}$. 
a
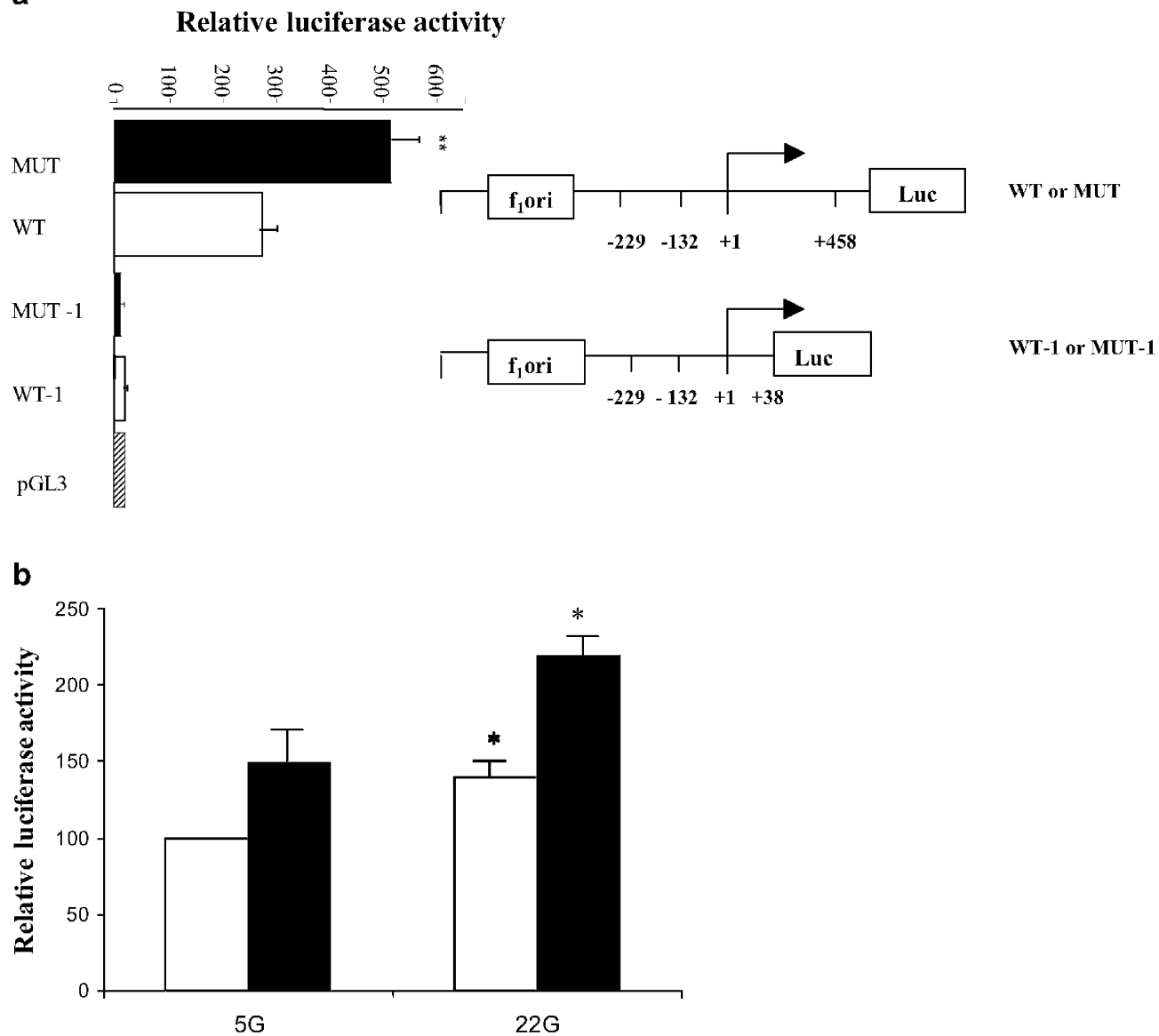

Fig. 1. Effect of the $G / A$ mutation (a) on the activity of the $I A P P$ promoter and the role of intron-1 sequence in this activity. The wild-type (WT) and the mutant (MUT) constructs with and without intron 1 sequence (WT-I and MUT-I respectively), as well as the plasmid control (pGL3, hatched bar), were transfected separately into MIN6 cells cultured at $22.7 \mathrm{mmol} / \mathrm{l}$ glucose. b. Effect of glucose on IAPP promoter activity. MIN6 cells transfected with the wild-type (white bars) and mutant (black bars) constructs were cultured for $24 \mathrm{~h}$ in $5.5 \mathrm{mmol} / \mathrm{l}$ glucose $(5 \mathrm{G})$ or in $22.7 \mathrm{mmol} / \mathrm{l}$ glucose $(22 \mathrm{G})$. Results are expressed as relative luciferase activity normalised to the activity of the co-transfected pRL-CMV renilla plasmid. Values are the mean \pm SEM from 10 to 15 experiments performed in triplicate. $* p<0.05$ vs WT or MUT; ** $p<0.001$ vs WT

Statistical analysis. Each experiment was repeated at least three times per condition. Data are presented as means \pm SEM. The statistical significance of the differences between experimental groups was evaluated by Student's unpaired two-tailed $t$ test and by the Kruskall-Wallis test. Differences were considered significant at a $p$ value of less than 0.05 .

\section{Results}

Islet amyloid polypeptide promoter activity in MIN6 cells. The promoter activity of the plasmid constructs containing the firefly luciferase reporter gene with the mutant or the wild-type sequence was analysed after transfection into MIN6 cells. The plasmid containing

the mutation showed a doubling of IAPP promoter activity compared with the wild-type construct $(p<0.001)$ (Fig. 1a). Glucose is regarded as a key regulator of the IAPP gene. To determine the effect of glucose on these constructions, transfected cells were incubated at 5.5 and $22.7 \mathrm{mmol} / \mathrm{l}$ glucose. Luciferase activity increased at high glucose concentrations in wild-type and mutant constructs $(p<0.05)$ (Fig. 1b). In all individual experiments, the activity of the mutant construct was higher than that of the wild-type construct, regardless of the glucose concentration in the culture medium. In addition, the activity of the promoter was almost completely abolished in the constructs lacking intron 1 (Fig. 1a).

Effect of agents modifying glucose metabolism, calcium channels and ATP-dependent potassium channel openers on IAPP promoter activity. The addition of $11.2 \mathrm{mmol} / \mathrm{l}$ 6-deoxy-D-glucose to $11.2 \mathrm{mmol} / \mathrm{l}$ glucose decreased luciferase activity of the wildtype construct by $25 \%$ when compared with the $22.7 \mathrm{mmol} / \mathrm{l}$ glucose control. Similarly, the addition of $11.2 \mathrm{mmol} / \mathrm{l}$ mannoheptulose to $22.7 \mathrm{mmol} / \mathrm{l}$ glucose decreased luciferase activity of the wild-type construct by $30 \%$ compared with high glucose alone. A similar pattern, but with higher luciferase activity, was observed when the mutant construct was transfected into MIN6 cells after the addition of the same test agents (43\% and 34\% decreases) (Fig. 2a). Moreover, in the 
a

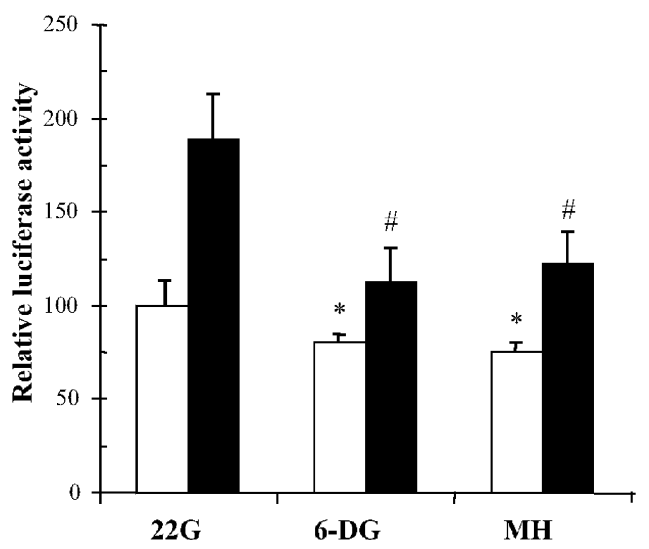

C

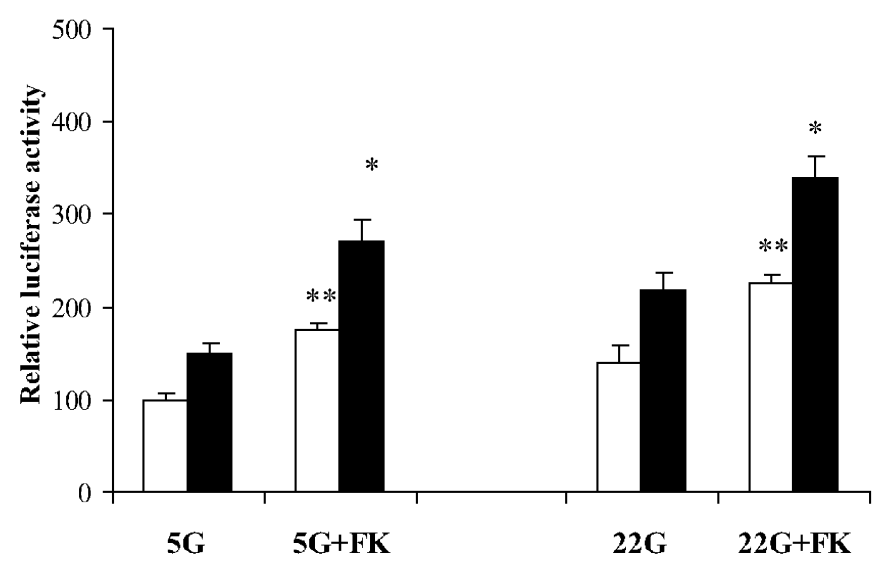

Fig. 2. Effect of glucose metabolism on IAPP promoter activity (a). MIN6 cells transfected with the wild-type (white bars) and mutant (black bars) constructs were cultured for $24 \mathrm{~h}$ in $22.7 \mathrm{mmol} / \mathrm{l}$ glucose $(22 \mathrm{G})$, in $11.2 \mathrm{mmol} / \mathrm{l}$ 6-deoxy-D-glucose (6-DG) plus $11.2 \mathrm{mmol} / 1 \mathrm{glucose}$ or in $11.2 \mathrm{mmol} / \mathrm{l}$ mannoheptulose $(\mathrm{MH})$ plus $22.7 \mathrm{mmol} / \mathrm{l}$ glucose. Results of luciferase activity are normalised to renilla activity and expressed as percentages of controls ( $22 \mathrm{G}$ wild-type). $* p<0.05$ vs $22 \mathrm{G}$ wildtype, \# $p<0.05$ vs $22 \mathrm{G}$ mutant. b. Effect of agents modifying calcium metabolism on IAPP promoter activity. MIN6 cells transfected as for (a) were cultured in $22.7 \mathrm{mmol} / \mathrm{l}$ glucose (22G) alone and in the presence of $100 \mu \mathrm{mol} / \mathrm{l}$ verapamil (VR) and $0.6 \mathrm{mmol} / \mathrm{l}$ diazoxide (DZ). Results are normalised and expressed as for (a). $* * p<0.001$ vs $22 \mathrm{G}$ wild-type; \#\# $p<0.001$ vs $22 \mathrm{G}$ mutant. c. Effect of cyclic AMP on IAPP promoter activity. MIN6 cells transfected as for (a) were cultured for $24 \mathrm{~h}$ in $5.5 \mathrm{mmol} / \mathrm{l}$ glucose $(5 \mathrm{G})$ or $22.7 \mathrm{mmol} / \mathrm{l}$ glucose $(22 \mathrm{G})$ alone or in the presence of $10 \mu \mathrm{mol} / \mathrm{l}$ forskolin (FK). Results are normalised and expressed as percentages of controls $(5 \mathrm{G}$ wildtype). $* p<0.05$ vs $5 \mathrm{G}$ mutant and $22 \mathrm{G}$ mutant; $* * p<0.01$ vs $5 \mathrm{G}$ wild-type and $22 \mathrm{G}$ wild-type. d. Effect of corticosteroids on IAPP promoter activity. MIN6 cells transfected as for (a) were cultured for $24 \mathrm{~h}$ in $5.5 \mathrm{mmol} / \mathrm{l}$ glucose $(5 \mathrm{G})$ or $22.7 \mathrm{mmol} / \mathrm{l}$ glucose $(22 \mathrm{G})$ alone or in the presence of $10 \mu \mathrm{mol} / \mathrm{l}$ dexamethasone (DX). Results are normalised and expressed as for (c). $* p<0.05$ vs $22 \mathrm{G}$ wild-type; $* * p<0.01$ vs $5 \mathrm{G}$ wild-type; \# $p<0.01$ vs $22 \mathrm{G}$ mutant; \#\# $p<0.001$ vs $5 \mathrm{G}$ mutant. All values are the mean \pm SEM from at least three experiments performed in triplicate b

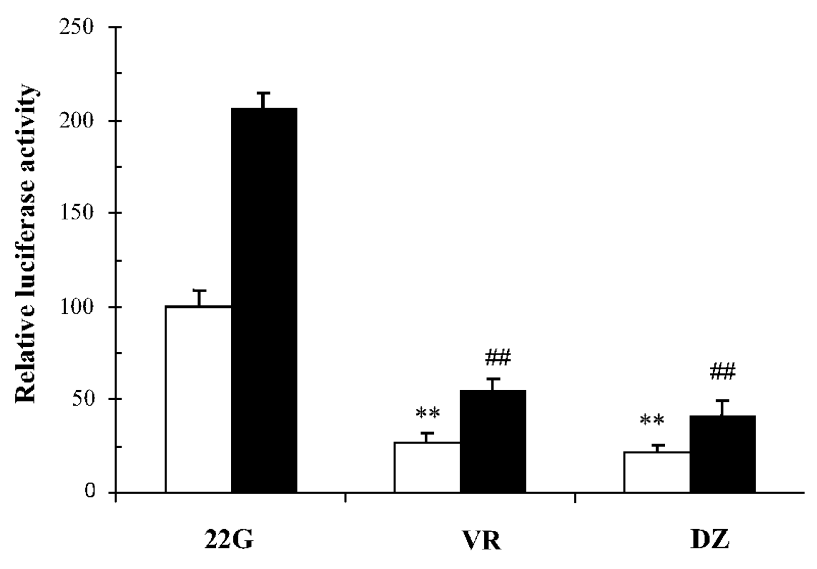

d

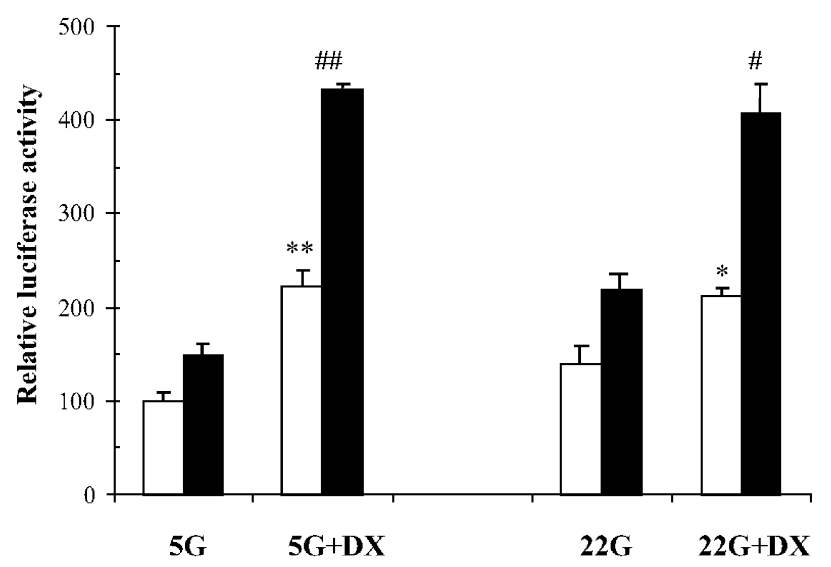

presence of the calcium channel blocker verapamil or the ATP-dependent potassium channel opener diazoxide, luciferase activity was inhibited by more than $70 \%(p<0.001)$ in all constructs (wild-type and mutant) (Fig. 2b).

Effect of cyclic AMP and corticosteroids on IAPP mutant promoter activity. Previous results indicate that intracellular second messengers like cAMP and corticosteroid play a role in the glucose regulation of IAPP gene expression [20,21]. Here, addition to the culture medium of the adenylate cyclase activator forskolin at $10 \mu \mathrm{mol} / \mathrm{l}$ increased luciferase activity of cells transfected with the wild-type and the mutant construct by $76 \%$ and $81 \%$ respectively, when cells were cultured in $5.5 \mathrm{mmol} / 1$ glucose. When cultures were maintained in $22.7 \mathrm{mmol} / \mathrm{l}$ glucose the increase was $67 \%$ and $56 \%$ respectively (Fig. 2c). Moreover, the addition of $10 \mu \mathrm{mol} / \mathrm{l}$ dexamethasone enhanced luciferase activity in cells transfected with the wild-type (120\% at $5.5 \mathrm{mmol} / \mathrm{l}$ glucose, $50 \%$ at $22.7 \mathrm{mmol} / 1$ glucose) and the mutant construct (180\% in low glucose, $85 \%$ in high glucose) (Fig. 2d).

DNA-nuclear protein complex analysis. All experiments indicated that the $-132 \mathrm{G} / \mathrm{A}$ mutation affects the basal but not the inducible transcription of the gene. Subsequent experiments were performed to 


\begin{tabular}{|lllllllll|}
\hline Glucose $5.5 \mathrm{mmol} / \mathrm{l}$ & + & + & - & - & - & - & - & - \\
Glucose $22.7 \mathrm{mmol} / \mathrm{l}$ & - & - & + & + & + & + & + & + \\
Forskolin $10 \mu \mathrm{mol} / \mathrm{l}$ & - & - & - & - & + & + & - & - \\
Dexamethasone $10 \mu \mathrm{mol} / \mathrm{l}$ & - & - & - & - & - & - & + & + \\
\hline
\end{tabular}

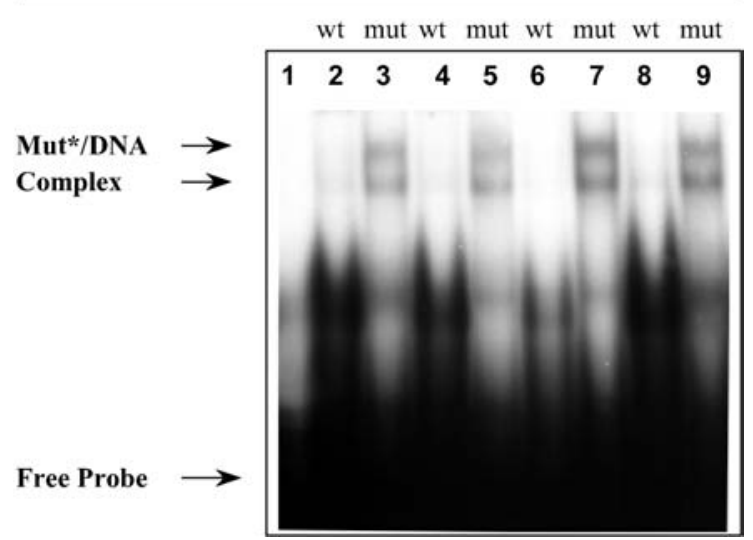

Fig. 3. Wild-type or mutant DNA binding from extracts of cells cultured in glucose (lanes 2, 3: $5.5 \mathrm{mmol} / \mathrm{l}$; lanes 4, 5: $22.7 \mathrm{mmol} / \mathrm{l}$; lanes 6, 7: $10 \mu \mathrm{mol} / 1$ forskolin plus $22.7 \mathrm{mmol} / \mathrm{l}$ glucose; lanes 8, 9: $10 \mu \mathrm{mol} / \mathrm{l}$ dexamethasone plus $22.7 \mathrm{mmol} / \mathrm{l}$ glucose). For the competition experiment, 100-fold excess of cold mutant oligonucleotide was included in the binding reaction (lane 1). The gel is representative of three independent experiments with qualitatively similar results. mt, mutant; wt, wild-type identify which potential nuclear proteins bind at this mutant site $(-132 \mathrm{bp})$. To analyse binding interactions, EMSAs were performed. At least two protein-DNA complexes were detected when the mutant oligonucleotide was tested (Fig. 3, lane 3). No signal was observed with the wild-type oligonucleotide (Fig. 3, lane 2). Several experiments were repeated to confirm these results. Moreover, the pattern of the bands did not vary in cultures maintained at low or high glucose concentrations when the mutant probe was tested (Fig. 3, lanes 3, 5). After the addition of $10 \mu \mathrm{mol} / 1$ forskolin or $10 \mu \mathrm{mol} / \mathrm{l}$ dexamethasone to the culture medium, the intensity of the bands with the mutant probe increased (Fig. 3, lanes 7, 9). However, there was no change when the wild-type probe was analysed in the same cultures (Fig. 3, lanes 6, 8). Treatment with verapamil and diazoxide did not affect the binding pattern, compared with the basal conditions, in either oligonucleotide (data not shown).

Competition assays were performed using $50 \times$ and $100 \times$ excess of cold oligonucleotides for: CRE, thyroid transcription factor (TTF-2) binding site, nuclear factors activation protein-1 (AP-1), glucocorticoid response element (GRE) and hepatocyte nuclear factor (HNF3) binding site. A clear competition with CRE was observed in the EMSA results (Fig. 4, lane 4), indicating that the mutant sequence creates a CRE-like

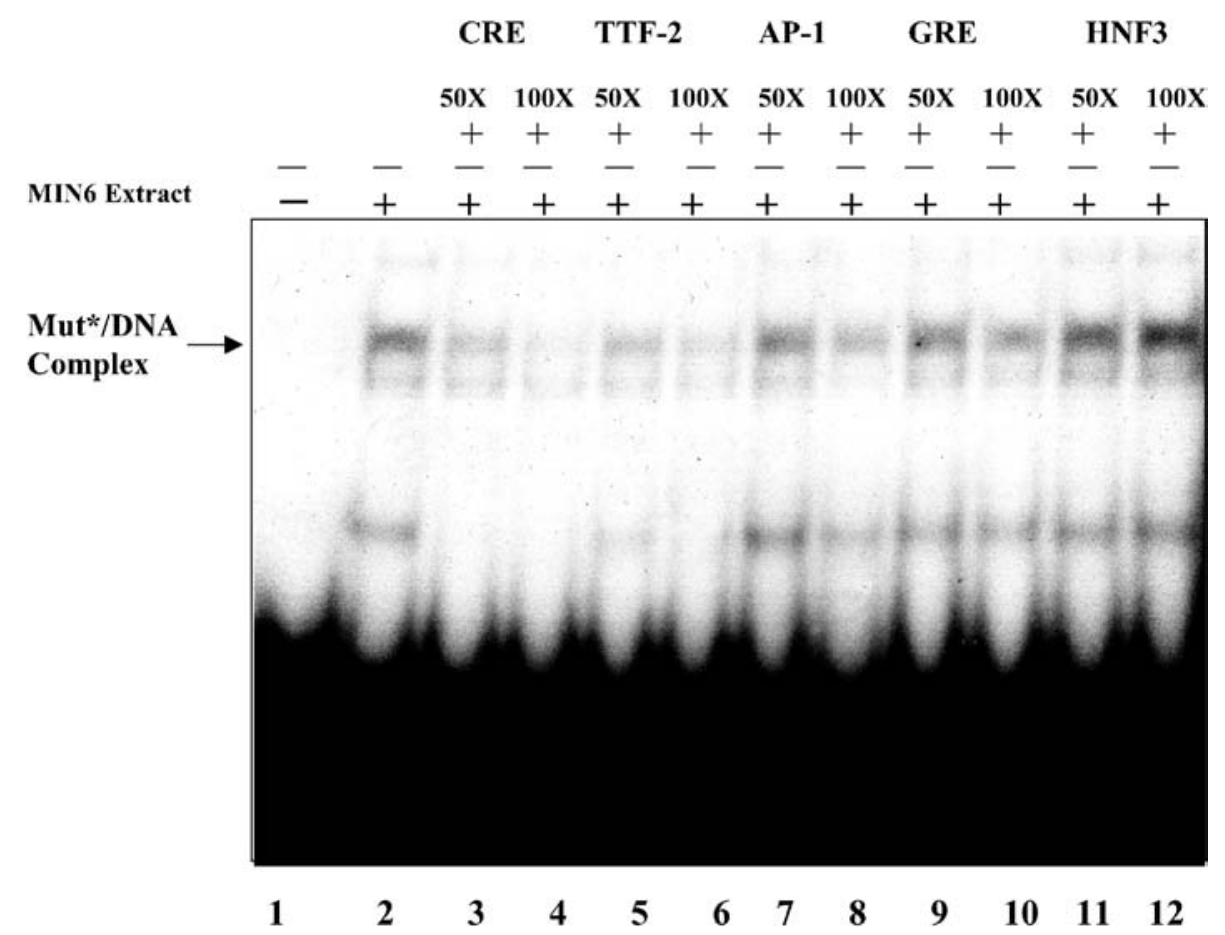

Fig. 4. Mutant or wild-type DNA binding with nuclear proteins. Competition experiments were performed on MIN6 cells cultured at $22.7 \mathrm{mmol} / \mathrm{l}$ glucose using related and unrelated oligonucleotides. Lane 1: free mutant probe without nuclear proteins; lane 2: mutant probe plus nuclear proteins. For competition assay a 50- or 100-fold excess of the unlabelled oligonucleotides were used as follows: CRE (cAMP-response element): lanes 3, 4; TTF-2 (thyroid transcription factor) binding site: lanes 5, 6; AP-1 (nuclear factors activation protein-1): lanes 7, 8; GRE (glucocorticoid response element): lanes 9, 10; HNF3 (hepatocyte nuclear factor) binding site: lanes 11, 12. A competitive activity was seen with 100 -fold excess of the unlabelled CRE and TTF-2 oligonucleotides with the mutant sequence (lanes 4,6 ). The protein-DNA complexes are indicated by arrows. The gel is representative of three independent experiments with qualitatively similar results 


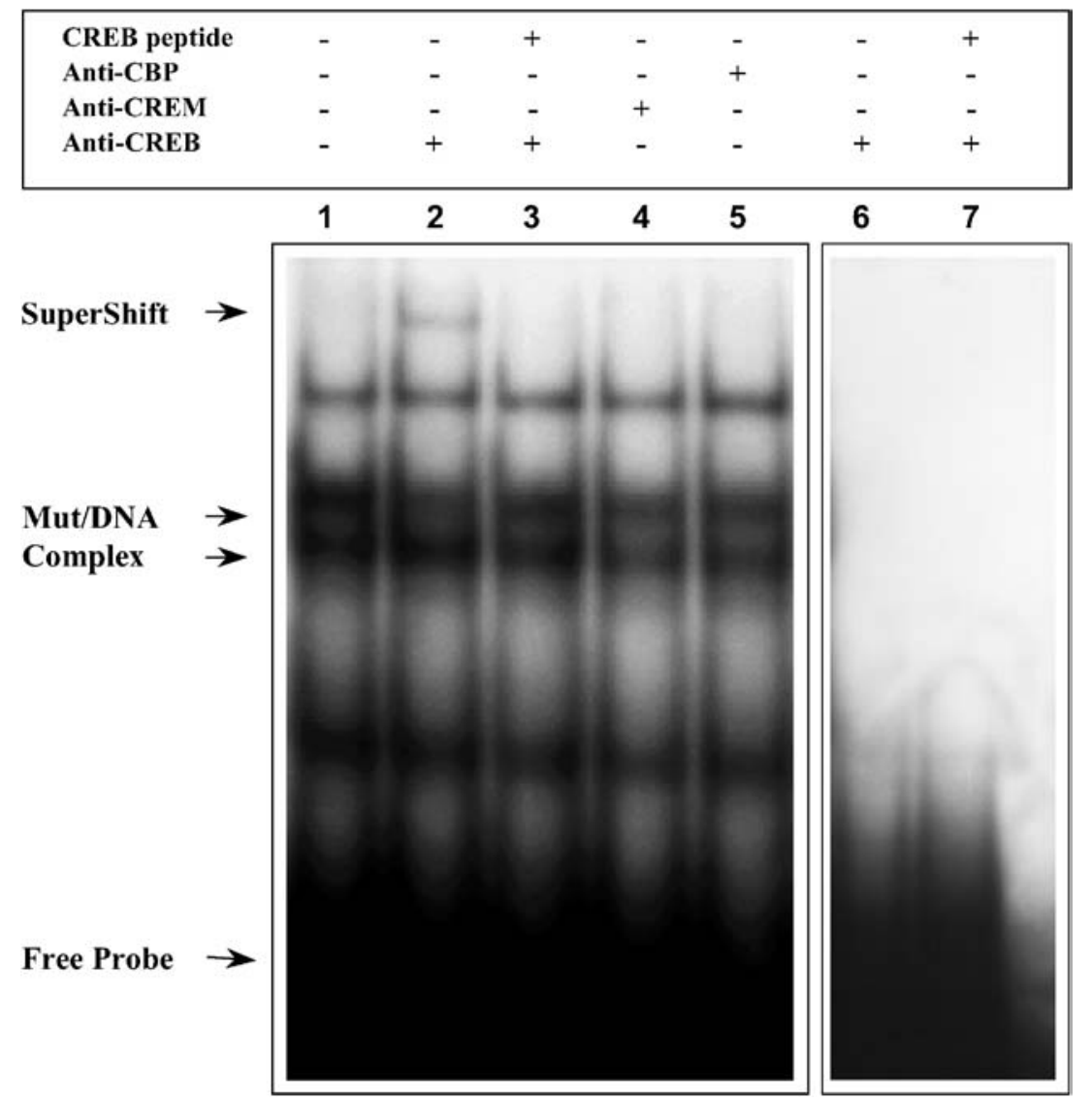

Fig. 5. Supershift assay using nuclear protein extracts from the MIN6 cell line treated with forskolin. The gel shift assay was done as described (see Methods). A supershift band was established by competition with an anti-CREB (cAMP-response element binding protein)-specific antibody (lane 2). The CREB peptide (lane 3) was used as a control of supershift specificity. No signal was observed when wild-type oligonucleotide was used in competition assay with the anti-CREB antibody (lane 6) or anti-CREB antibody plus CREB peptide (lane 7). Protein-DNA and supershift complexes are indicated by arrows. The gel is representative of three independent experiments with qualitatively similar results. CBP, cAMP-binding protein; CREM, cAMP response element modulator

sequence, which may partly explain the enhanced activity of the mutated construct in all experimental conditions. While slight competition with TTF-2 was detected (Fig. 4, lane 6), no competition was observed for the other consensus sequences used, i.e. AP-1, GRE and HNF3 binding site.

To identify some of the transcription factors involved in the regulation of the mutant construct of the IAPP gene, we performed a super-shift EMSA to test antiCREB, anti-CREM and anti-CBP antibodies, which detect proteins related to CRE. A super-shifted band was identified in MIN6 cell nuclear proteins by competition with an anti-CREB-specific antibody (Fig. 5, lane 2). When CREB peptide was added to the reaction mix, the retarded complex was completely abolished, thus confirming the specificity of the band (Fig. 5, lane 3).

\section{Discussion}

Several mutations have been described in the promoter region of the IAPP gene, one of which is located at the position $-132 \mathrm{G} / \mathrm{A}$, within an enhancer domain of the IAPP promoter $[13,14,15,16]$. However, the potential role of this mutation in the abnormal regulation or expression of the peptide and its correlation with Type 2 diabetes are unclear. Here, we show that this mutation increases the basal transcriptional activity of the IAPP gene, without any change in inducible transcription compared with the wild-type sequence. Furthermore, the activity of the intronless construct was almost abolished. The decrease in the luciferase activity of this construct may result from a lower efficiency of translation because of the lack of intron 1, which appears to be involved in the post-transcriptional regulation of IAPP expression, as reported elsewhere $[22,23]$.

We studied the functional properties of the wildtype and the mutant promoter. We first tested whether signals derived from glucose metabolism are involved in the modulation of IAPP promoter activity (wildtype sequence) and whether the mutation studied interferes with such regulation. At high concentrations, glucose stimulates IAPP gene expression in pancreatic islets, which requires intracellular metabolism of the hexose $[20,21]$. In the current study, mannoheptulose, an inhibitor of beta cell glucokinase, abolished the stimulatory effect of high glucose on IAPP promoter 
activity, suggesting that signals derived from glucose metabolism are necessary for transcriptional activation of the wild-type and mutant IAPP genes. This was confirmed by using the non-metabolisable glucose analogue 6-deoxy-D-glucose, which did not increase transcriptional activity when added to the culture media. Under both conditions, the mutant constructs showed the same pattern of response as the wild-type constructs, but with higher activity.

The link between glucose metabolism and IAPP gene expression may be in the calcium signalling pathway. Previous results show that diazoxide and verapamil inhibit IAPP secretion and the expression of IAPP mRNA levels elicited by high glucose [20], suggesting that calcium plays a crucial role in mediating the response of the IAPP gene to glucose addition. In the present study, verapamil and diazoxide inhibited the promoter activity of both constructs, as reported elsewhere [24], which demonstrates that glucose regulation of IAPP gene transcription depends on calcium concentrations.

Given that glucose metabolism increases cAMP and IAPP mRNA levels in pancreatic beta cells [20, 24], we next investigated the involvement of this pathway in the regulation of IAPP promoter activity. Cyclic AMP response elements have been described in the promoter region of the IAPP gene. Although they were found to be non-functional in other studies [25], we showed that forskolin stimulates IAPP promoter activity. Moreover, this agent exerts its effect regardless of the glucose concentrations in the culture medium, which suggests that glucose and forskolin regulate transcriptional activity of the IAPP gene through distinct signalling pathways, as reported elsewhere [26]. Interestingly, the mutant constructs reproduced the same pattern as the wild-type constructs but at higher levels of activity.

The effect of dexamethasone on the activity of the $I A P P$ promoter was also analysed. Regulation of IAPP gene expression does not parallel that of insulin in dexamethasone-treated rats [27, 28], which suggests that glucocorticoids contribute to the transcriptional regulation of the IAPP gene. Although a GRE consensus sequence has not been identified in the $I A P P$ gene, there is a similar sequence in intron 1 of the IAPP gene [29]. Multiple positive and negative elements flanking the IAPP gene, e.g. the E2 domainlike sequence, the CRE-like sequence and others including elements in the position $(-138 /-122)$, have been described [22, 30]. However, the role of these elements in the transcriptional activity of the gene remains poorly understood. Furthermore, the nuclear proteins involved in the regulation of the gene through binding to these elements are unknown. EMSA revealed that DNA binding was elicited by the mutant probe, and that this was enhanced by the addition of forskolin and glucocorticoids to the culture media. After competition experiments, we propose that the $-132 \mathrm{bp} G / A$ mutation in the promoter region creates a new binding site, which is recognised as a CRE-like regulatory element. Also, when the binding site for the forkhead TTF-2 was used as an unrelated oligonucleotide, slight competition was observed. The exact meaning of this result is unknown, but could be explained by the fact that TTF- 2 is under cAMP regulation [31].

The supershift analysis showed specific DNA binding for CREB protein, indicating that at least this transcription factor is involved in this new CRE-like sequence. The CRE is also a pleiotropic element that is crucial for basal transcription, the cAMP response and the glucocorticoid response. CREB binds to CRE to mediate the cAMP response, whereas other family members bind to the same sequence to confer accessory activity to the glucocorticoid. The role of these CRE-binding factors in the glucocorticoid response is unclear. Recent findings have identified c/EBPbeta, an accessory factor that, through binding to CRE, induces transcription in response to glucocorticoids [32]. These interactions may help to explain the corticoid effect observed in our experiments.

In previous studies we showed [33] that high glucose concentrations provoke a substantial increase in intracellular IAPP in human pancreatic islets. Under such conditions, the capacity of the cell-regulated secretory mechanisms may become overwhelmed and selective release or destinations of IAPP via alternative pathways may occur. In fact evidence for this mechanism has been reported by other authors [34]. Because of the relevance of amyloid deposition in humans, we hypothesise that the high rate of transcriptional activity produced by the mutant could be related to high production of IAPP and in consequence activation of the constitutive secretory pathway. Further studies are required to elucidate whether these mechanisms could be involved in amyloidogenesis.

In conclusion, the transcriptional activation of the wild-type and mutant IAPP genes was regulated in parallel in all experimental conditions, strongly indicating that the $-132 \mathrm{G} / \mathrm{A}$ mutation influences basal but not inducible transcription. New binding to the mutant region through the CREB protein and other transcription factors not yet identified may account for these results.

Acknowledgements. This study was supported by grants from Marato TV3 (1998/ 991730/31/32), FIS (99/0378), FIS P1020931, RCMN (C03/08) and RGDM (G03/212) from Ministerio de Sanidad y Consumo (Spain).

\section{References}

1. Cooper GJS, Willis AC, Clark A, Turner RC, Sim R, Reid KBM (1987) Purification and characterization of a peptide from amyloid-rich pancreases of Type 2 diabetic patients. Proc Natl Acad Sci USA 84:8628-8632 
2. Nishi M, Sanke T, Nagamatsu S, Bell GI, Steiner DF (1990) Islet amyloid polypeptide: a new-cell secretory product related to islet amyloid deposits. J Biol Chem 265:4173-4176

3. Westermark P, Wernstedt C, Wilander E, Hayden DW, O'Brien TD, Johnson KH (1987) Amyloid fibrils in human insulinoma and islets of Langerhans of the diabetic cat are derived from a neuropeptide-like protein also present in normal islet cells. Proc Natl Acad Sci USA 84:3881-3885

4. Clark A, Wells C, Buley ID et al. (1988) Islet amyloid, increased A-cells, reduced beta-cells and exocrine fibrosis: quantitative changes in the pancreas in Type 2 diabetes. Diabetes Res 9:151-159

5. Kahn SE, Andrikopoulos S, Verchere CB (1999) Islet amyloid: a long recognized but underappreciated pathological feature of Type 2 diabetes. Diabetes 48:241-253

6. Höppener JW, Ahrén B, Lips CJM (2000) Islet amyloid and Type 2 diabetes mellitus. N Engl J Med 343:411-419

7. Westermark P, Engstrom U, Johnson KH, Westermark GT, Betscholtz C (1990) Islet amyloid polypeptide: pinpointing amino acid residues linked to amyloid fibril formation. Proc Natl Acad Sci USA 87:5036-5045

8. Castillo GM, Cummings JA, Yang W et al. (1998) Sulfate content and specific glycosaminoglycan backbone of perlecan are critical for perlecan's enhancement of islet amyloid polypetide (amylin) fibril formation. Diabetes 47:612-620

9. DeKoning EJ, Morris ER, Hofhuis FM et al. (1994) Intra and extracellular amyloid fibrils are formed in cultured pancreatic islets of transgenic mice expressing human islet amyloid polypeptide. Proc Natl Acad Sci USA 91:8467-8471

10. Verchere CB, D’Alessio DA, Palmiter RD et al. (1996) Islet amyloid formation associated with hyperglycemia in transgenic mice with pancreatic beta cell expression of human islet amyloid polypeptide. Proc Natl Acad Sci USA 93:3492-3496

11. Janson J, Soeller WC, Roche PC et al. (1996) Spontaneous diabetes mellitus in transgenic mice expressing human amyloid polypeptide. Proc Natl Acad Sci USA 93:7283-7288

12. German MS, Moss LG, Wang J, Rutter WJ (1992) The insulin and islet amyloid polypeptide genes contain similar cell-specific promoter elements that bind identical beta-cell nuclear complexes. Mol Cell Biol 12:1777-1788

13. Novials A, Rojas I, Franco C, Casamitjana R, Usac EF, Gomis R (2001) A novel mutation in islet amyloid polypeptide (IAPP) gene promoter is associated with Type II diabetes mellitus. Diabetologia 44:1064-1065

14. Poa NR, Cooper GJS, Edgar PF (2003) Amylin gene promoter mutations predispose to Type 2 diabetes in New Zealand Maori. Diabetologia 46:574-578

15. Pildal J, Lajer SK, Almind K et al. (2003) Studies of variability in the islet amyloid polypeptide gene in relation to Type 2 diabetes. Diabetic Med 20:491-494

16. Novials A, Kistauri A, Chico A, Gomis R (2003) To: Poa NR, Cooper GJX, Edgar PF: Amylin gene promoter mutations predispose to Type 2 diabetes in New Zealand Maori. Diabetologia 46:574-578. Diabetologia 46:17081709

17. Ishihara H, Asano T, Tsukuda K et al. (1993) Pancreatic beta-cell line MIN6 exhibits characteristics of glucose metabolism and glucose-stimulated insulin secretion similar to those of normal islets. Diabetologia 36:1139-1145

18. Andrews NC, Faller DV (1991) A rapid micropreparation technique for extraction of DNA-binding proteins from limiting numbers of mammalian cells. Nucleic Acids Res 19:2499
19. Santisteban P, Acebrón A, Polycarpou-Schwartz M, Di Lauro R (1992) Insulin and insulin-like growth factor I regulate a thyroid-specific nuclear protein that binds to the thyroglobulin promoter. Mol Endocrinol 6:1310-1317

20. Gasa R, Gomis R, Casamitjana R, Rivera F, Novials A (1997) Glucose regulation of islet amyloid polypeptide gene expression in rat pancreatic islets. Am J Physiol 272:E543-E549

21. Gasa R, Gomis R, Casamitjana R, Novials A (1997) Signals related to glucose metabolism regulate islet amyloid polypeptide (IAPP) gene expression in human pancreatic islets. Regul Pept 68:99-104

22. Carty MD, Lillquist JS, Peshavaria M, Stein R, Soeller WC (1997) Identification of cis-and trans-active factors regulating human islet amyloid polypeptide gene expression in pancreatic beta-cells. J Biol Chem 272:11986-11993

23. Ekawa K, Nishi M, Ohagi S, Sanke T, Nanjo K (1997) Cloning of mouse islet amyloid polypeptide gene and characterization of its promoter. J Mol Endocrinol 19:7986

24. Mcfarlane WM, Campbell SC, Elrick LJ et al. (2000) Glucose regulates islet amyloid polypeptide gene transcription in a PDX1- and calcium-dependent manner. J Biol Chem 275:15330-15335

25. Mosselman S, Höppener JW, With L, Soeller WC, Lips CJM, Jansz HS (1990) IAPP/amylin gene transcriptional control region: evidence for negative regulation. FEBS Lett 271:33-36

26. Ding WQ, Holicky E, Miller J (2001) Glucose and forskolin regulate IAPP gene expression through different signal transduction pathways. Am J Physiol Endocrinol Metab 281:E938-E945

27. Koranyi L, Bourey R, Turk J, Mueckler M, Permutt MA (1992) Differential expression of rat pancreatic islet betacell glucose transporter (GLUT 2), proinsulin and islet amyloid polypeptide genes after prolonged fasting, insulininduced hypoglycemia and dexamethasone treatment. Diabetologia 35:1125-1132

28. Mulder H, Ahrén B, Stridsberg M, Sundler F (1995) Nonparallelism of islet amyloid polypeptide (amylin) and insulin gene expression in rat islets following dexamethasone treatment. Diabetologia 38:395-402

29. Garlatti M, Daheshia M, Slater E et al. (1994) A functional glucocorticoid-responsive unit composed of two overlapping inactive receptor-binding sites: evidence for formation of a receptor tetramer. Mol Cell Biol 14:8007-8017

30. Bretherton-Watt D, Gore N, Boam DS (1996) Insulin upstream factor 1 and a novel ubiquitous factor bind to the human islet amyloid polypeptide/amylin gene promoter. Biochem J 313:495-502

31. Ortiz L, Zannini M, Di Lauro R, Santisteban P (1997) Transcriptional control of the forkhead thyroid transcription factor TTF-2 by thyrotropin, insulin, and insulin-like growth factor. J Biol Chem 272:23334-23339

32. Yamada K, Duong DT, Scott DK, Wang JC, Granner DK (1999) CCAAT/enhancer-binding protein beta is an accessory factor for the glucocorticoid response from the cAMP response element in the rat phosphoenolpyruvate carboxykinase gene promoter. J Biol Chem 274:5880-5887

33. Gasa R, Gomis R, Casamitjana R, Novials A (2001) High glucose concentration favors the selective secretion of islet amyloid polypeptide through a constitutive secretor pathway in human pancreatic islet. Pancreas 22:307-310

34. Kahn SE, Verchere CB, D'Alessio DA et al. (1993) Evidence for selective release of rodent islet amyloid polypeptide through the constitutive secretory pathway. Diabetologia 36:570-573 